\title{
TRNA Methyltransferase
}

National Cancer Institute

\section{Source}

National Cancer Institute. tRNA Methyltransferase. NCI Thesaurus. Code C17107.

An enzyme that catalyzes the methylation of transfer RNAs. 